\title{
The Peculiar Case of Deep Sierran Earthquakes
}

Craig H. Jones, Jamie Ryan, Andy Frassetto, Jeffrey R. Unruh, and Hersh Gilbert

P.S.: June 2022, Thompson Field Forum in the Sierra addressing age of uplift

(Leaders: Cassel, Henry, Jones, Wakabayashi)

Cordilleran GSA, Spring 2021 


\section{USGS Earthquakes, 1990-present, $M \geq 4$}

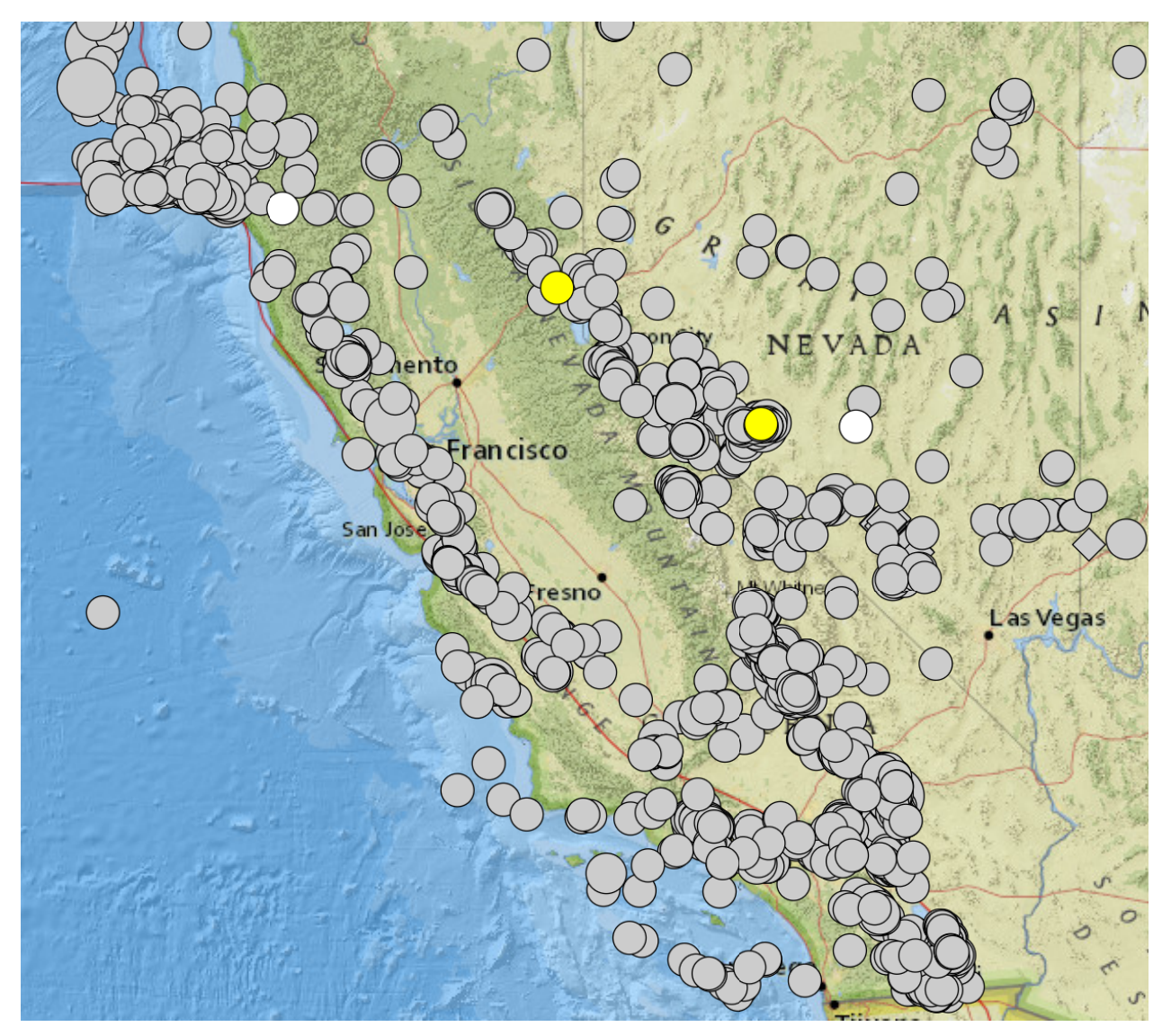

Usually when we worry about EQs in CA, we look at these places... and assume Sierra rigid. 


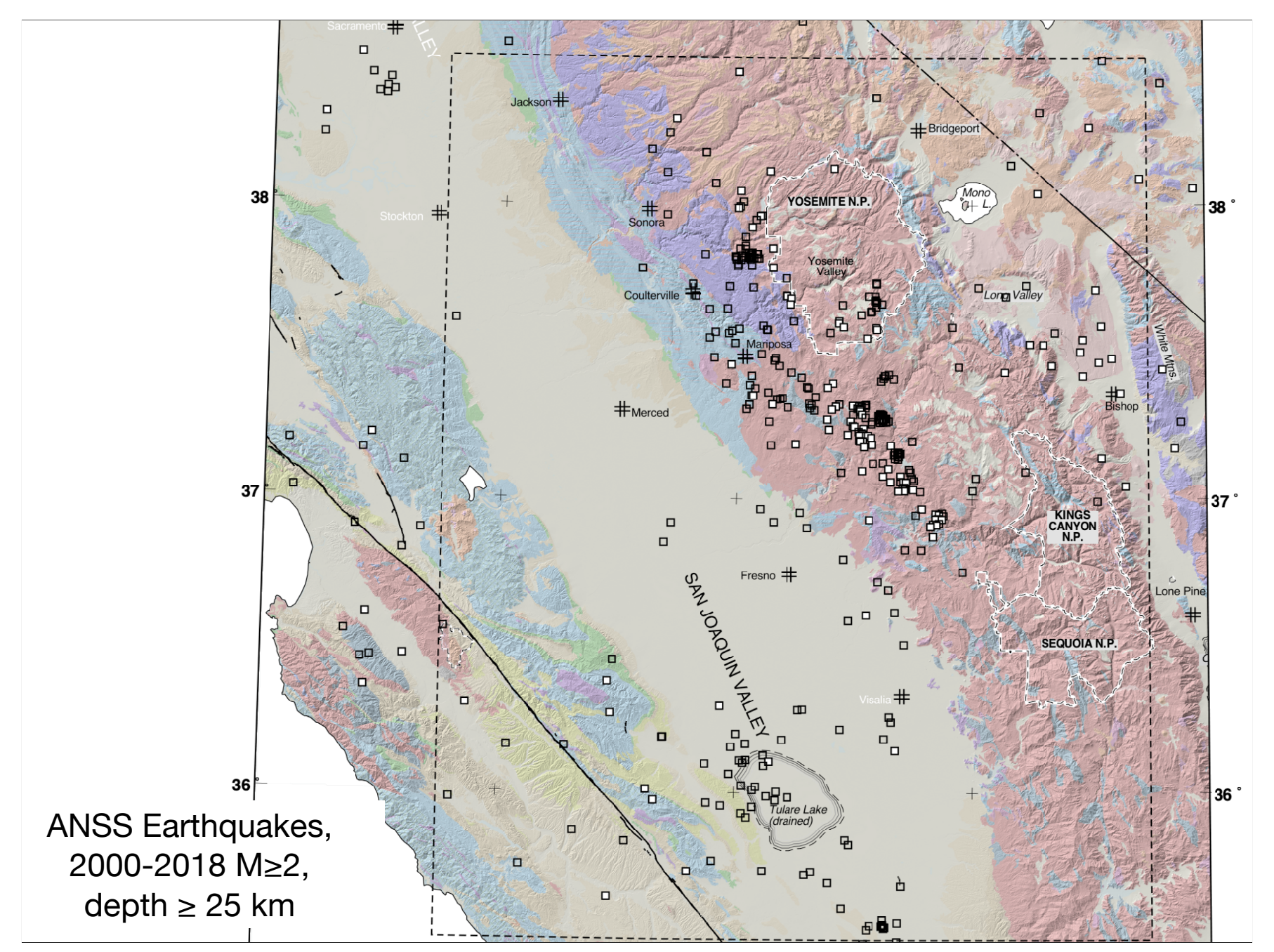

OK, so there are deep earthquakes...so what? Not any obvious connection to surface geology (unless you think Melones FZ continues deep in subsurface to SE). Recall lots of EQs to east and west. Not so many deep ones there... 


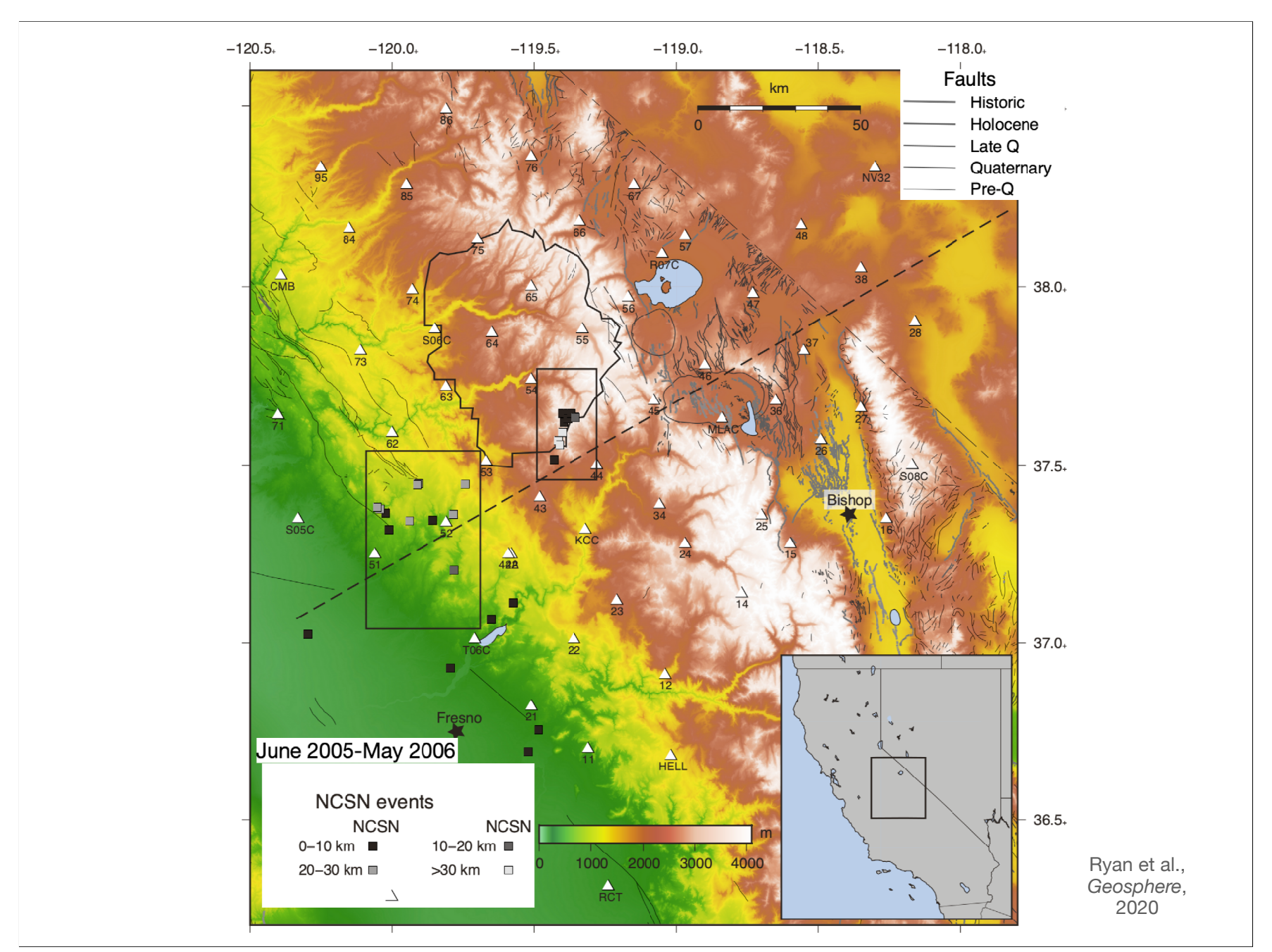

But otherwise most seismometers far away until SNEP deployment in 2005. First year of SNEP allowed examination of earthquakes in Sierra foothills. Network locations shown here... 


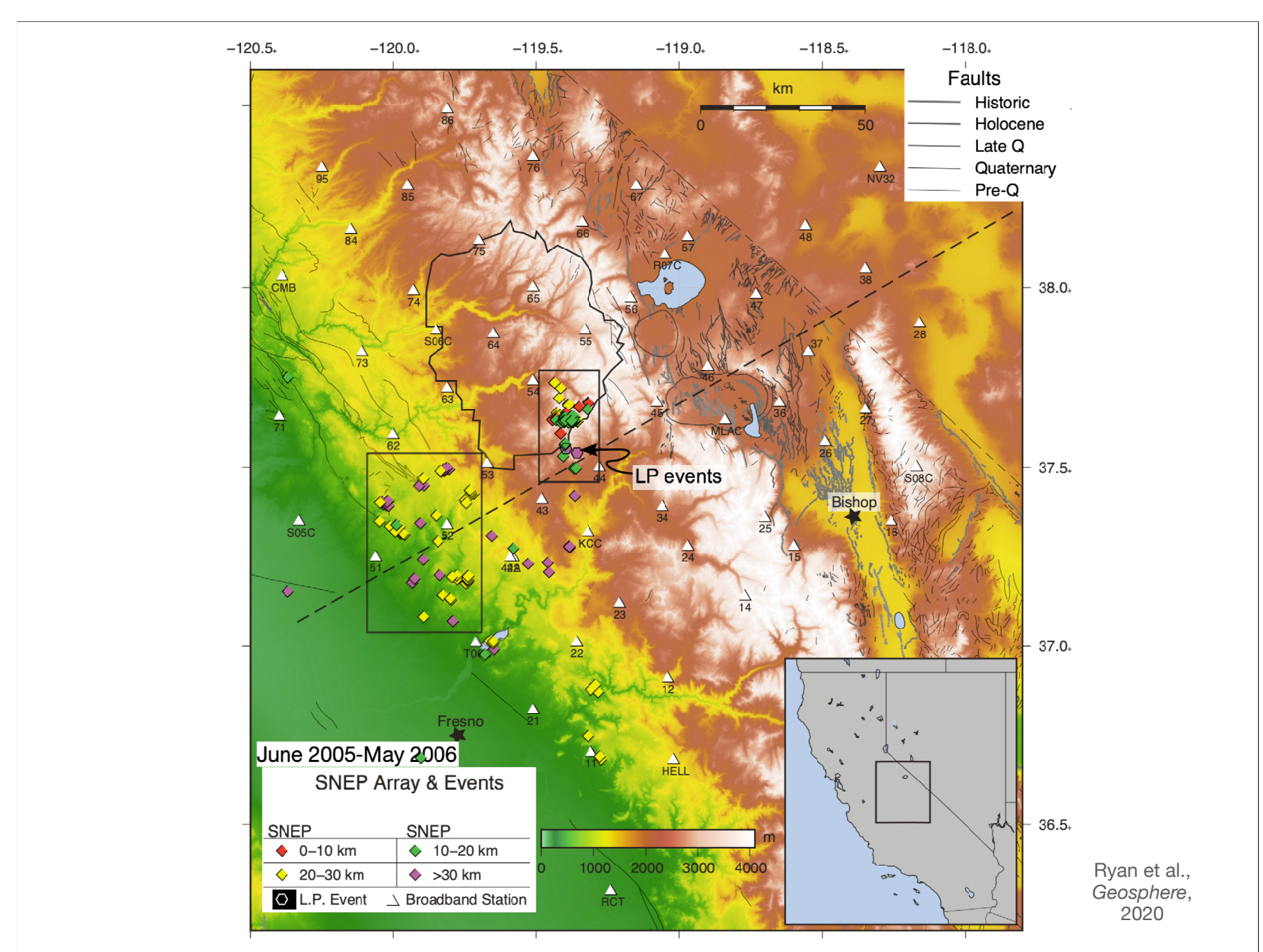

But locations with the SNEP array moved shallow events in the west to greater depth (similar to Wong work) 


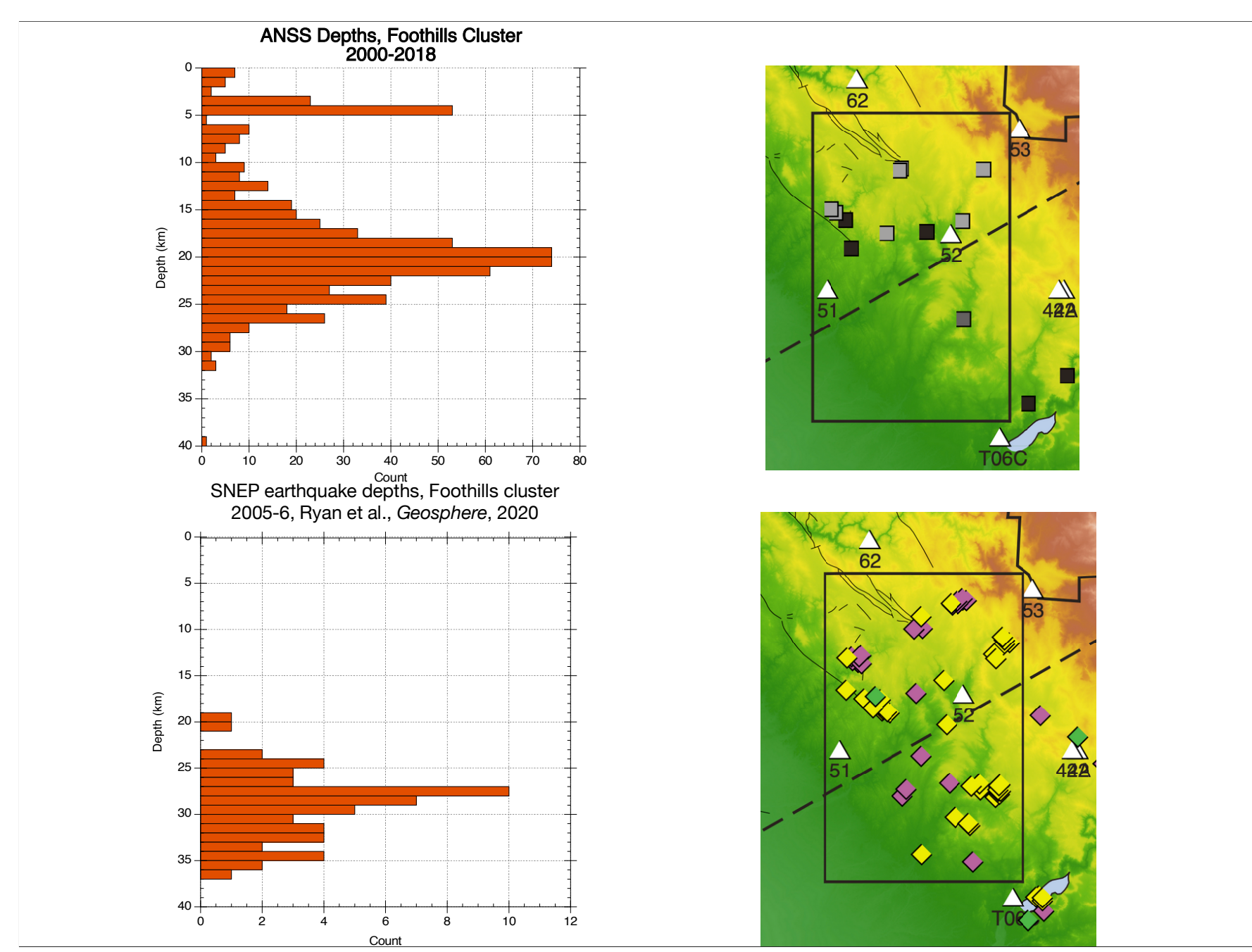

Absence of deep quakes in the foothills seems pretty strong-stations right above quakes. 


\section{Three Questions:}

1. How special is this?

2. How might this work?

3. What might this mean for regional tectonics?

SNEP earthquake depths, Foothills cluster
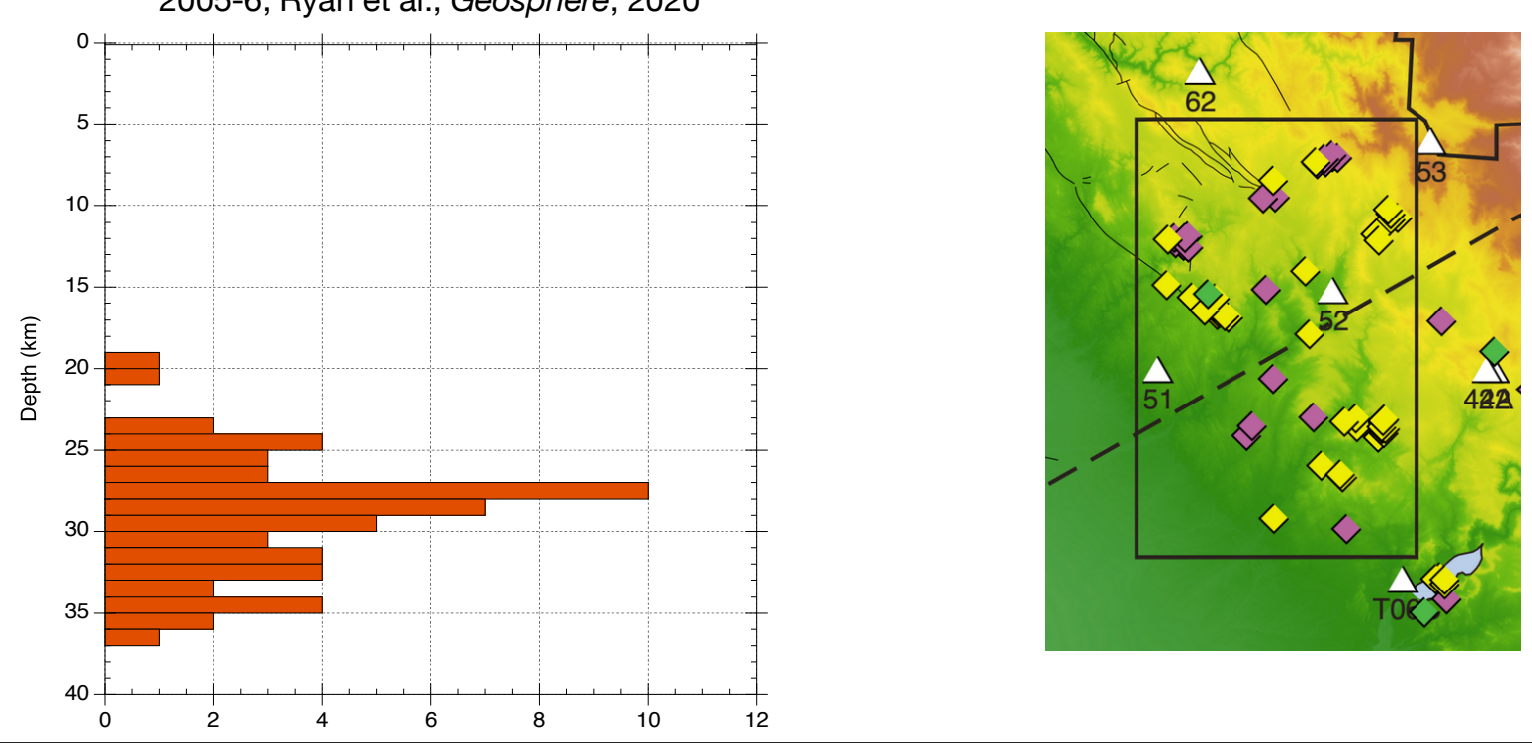

Poses three questions... 


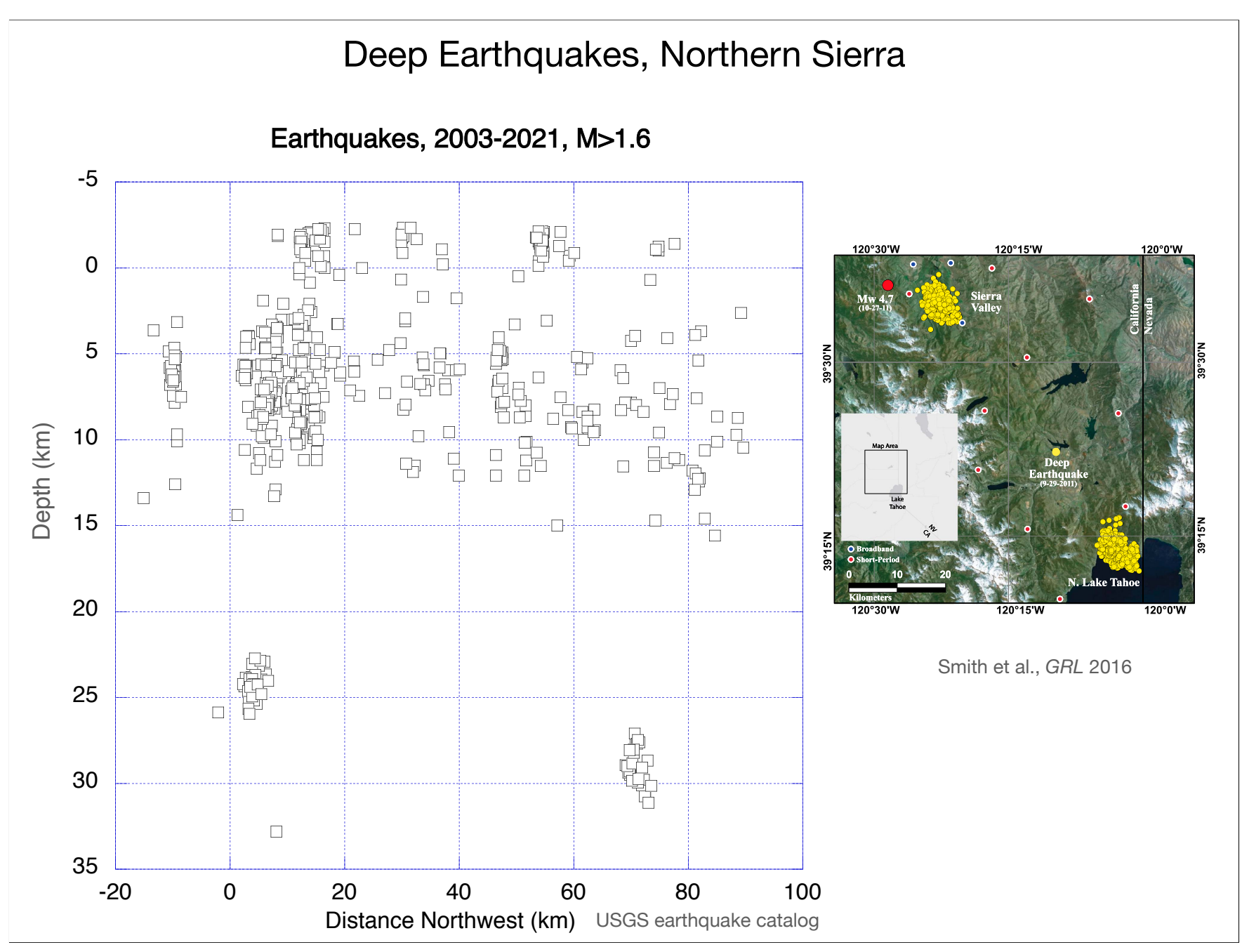

But while those quakes are present, there is lots of upper crustal seismicity. Also note that there are fairly young surface volcanics present which don't exist in the Sierra foothills. 


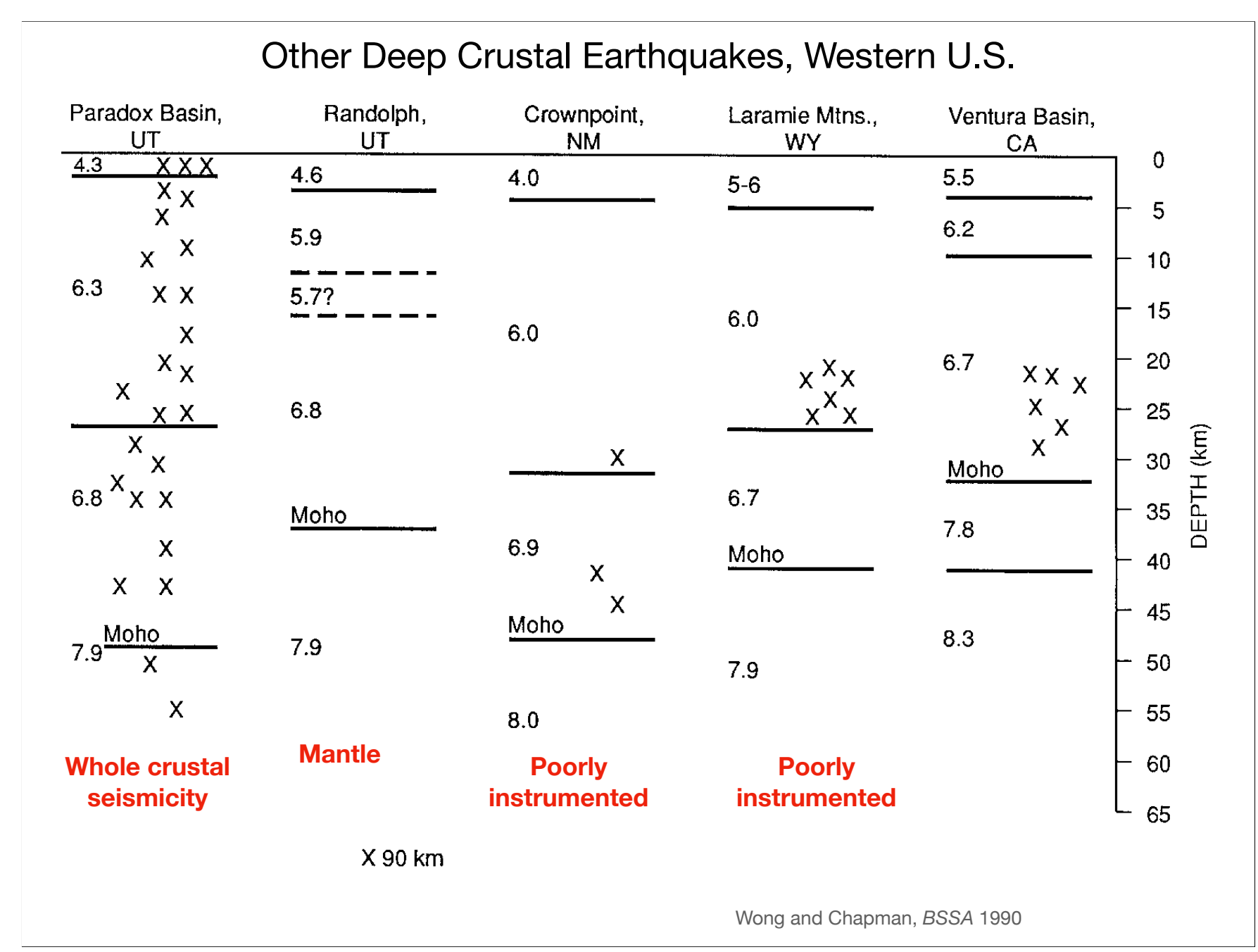

Other places in WUS with deep EQs. Most of these either have upper crustal quakes or are too poorly monitored to know. So while deep EQs aren't that unusual, an absence of shallow EQs is. 
Other Deep Crustal Earthquakes, Global

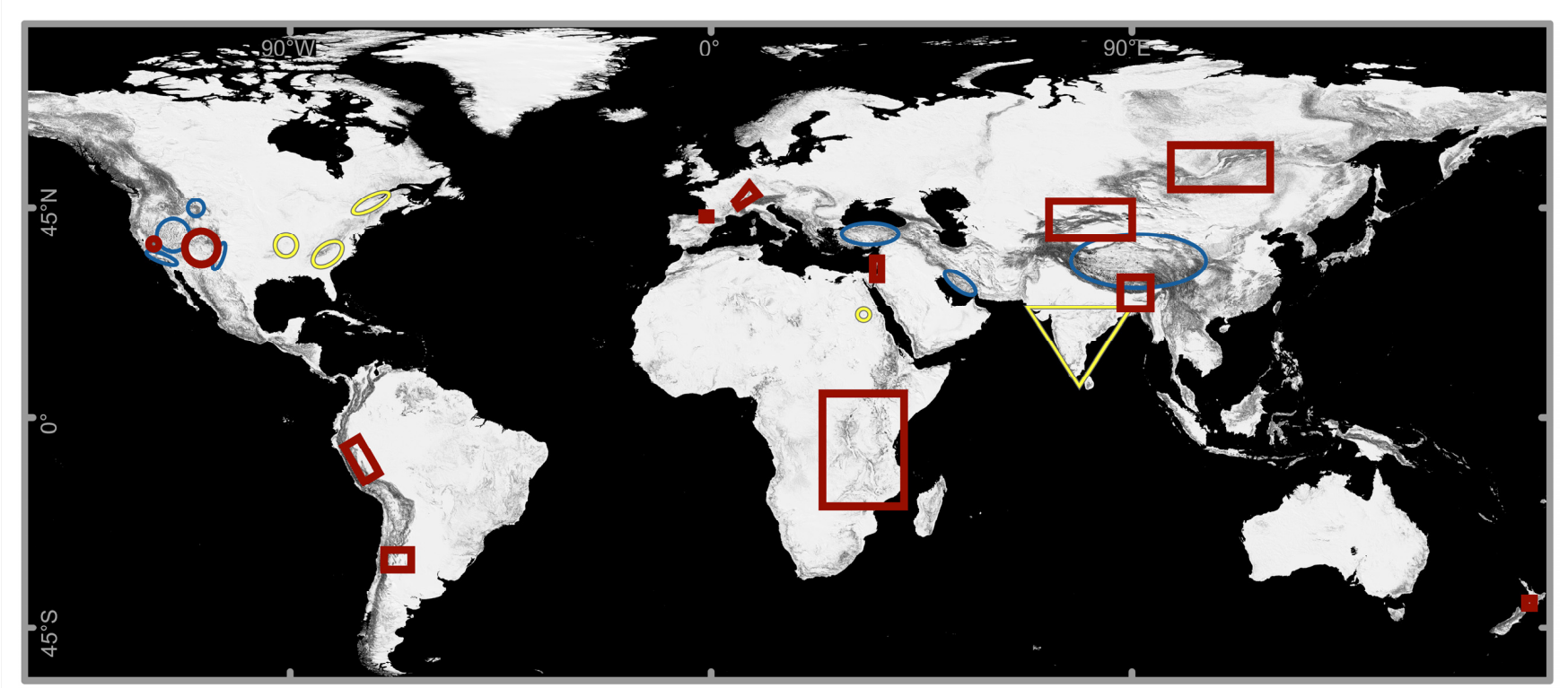

Tectonically active continental areas that exhibit a seismic lower crust (Figure 3.2)

Tectonically active continental areas that exhibit an aseismic lower crust (Figure 3.3) Stable Continental Regions (Figure 3.4)

So how does this compare globally? Thesis by Stephanie Devlin sought out deep crustal earthquakes... 
Three Questions:

1. How special is this?-Seems pretty special

2. How might this work?

3. What might this mean for regional tectonics?

SNEP earthquake depths, Foothills cluster 2005-6, Ryan et al., Geosphere, 2020
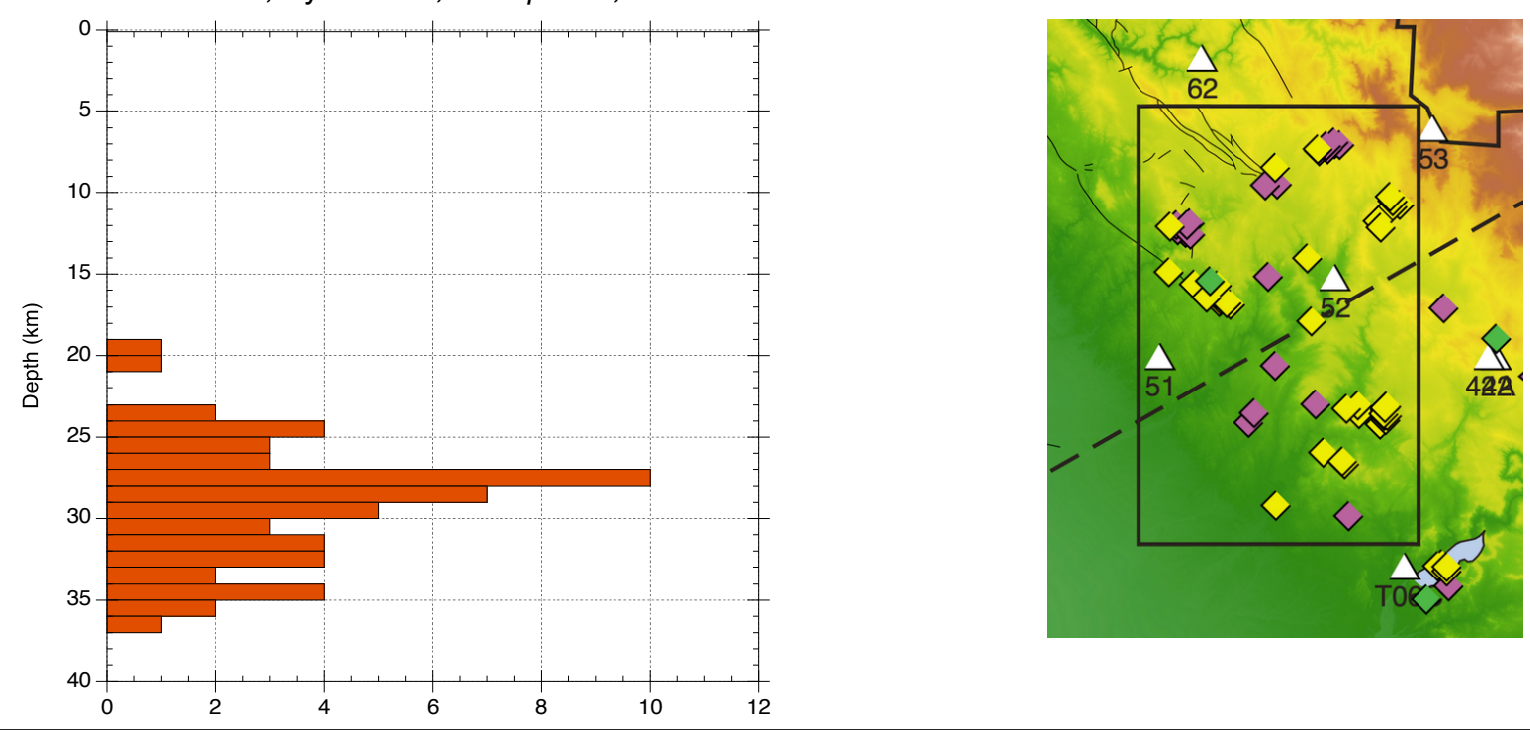

So this does seem quite unusual. 

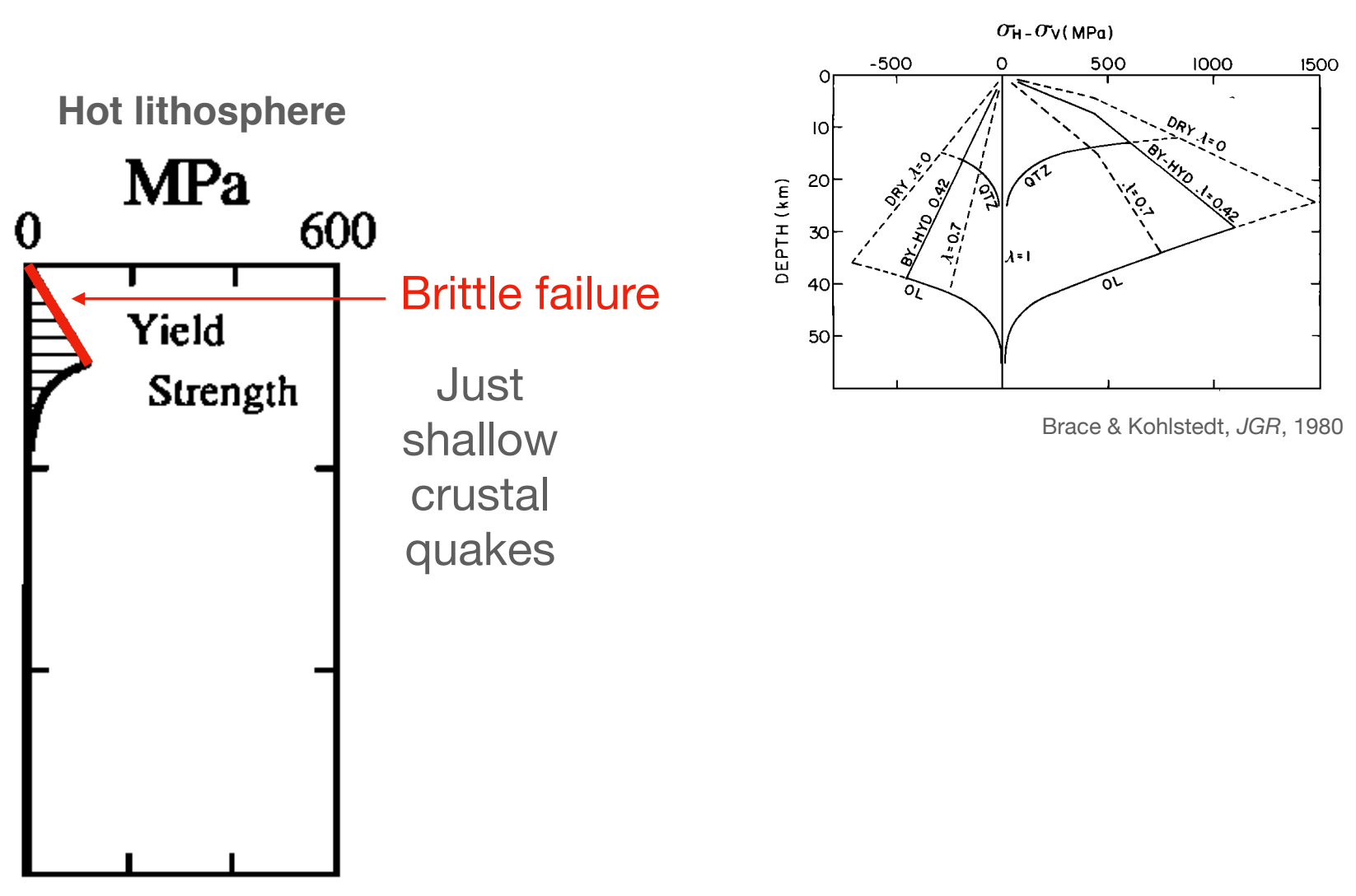

Normally we think of the lithosphere as behaving brittlely at shallower depths and ductilely at greater depths, with the brittle-ductile boundary reflecting an isotherm within a given petrology. SO if things are hot, just upper crust suffering brittle failure. 


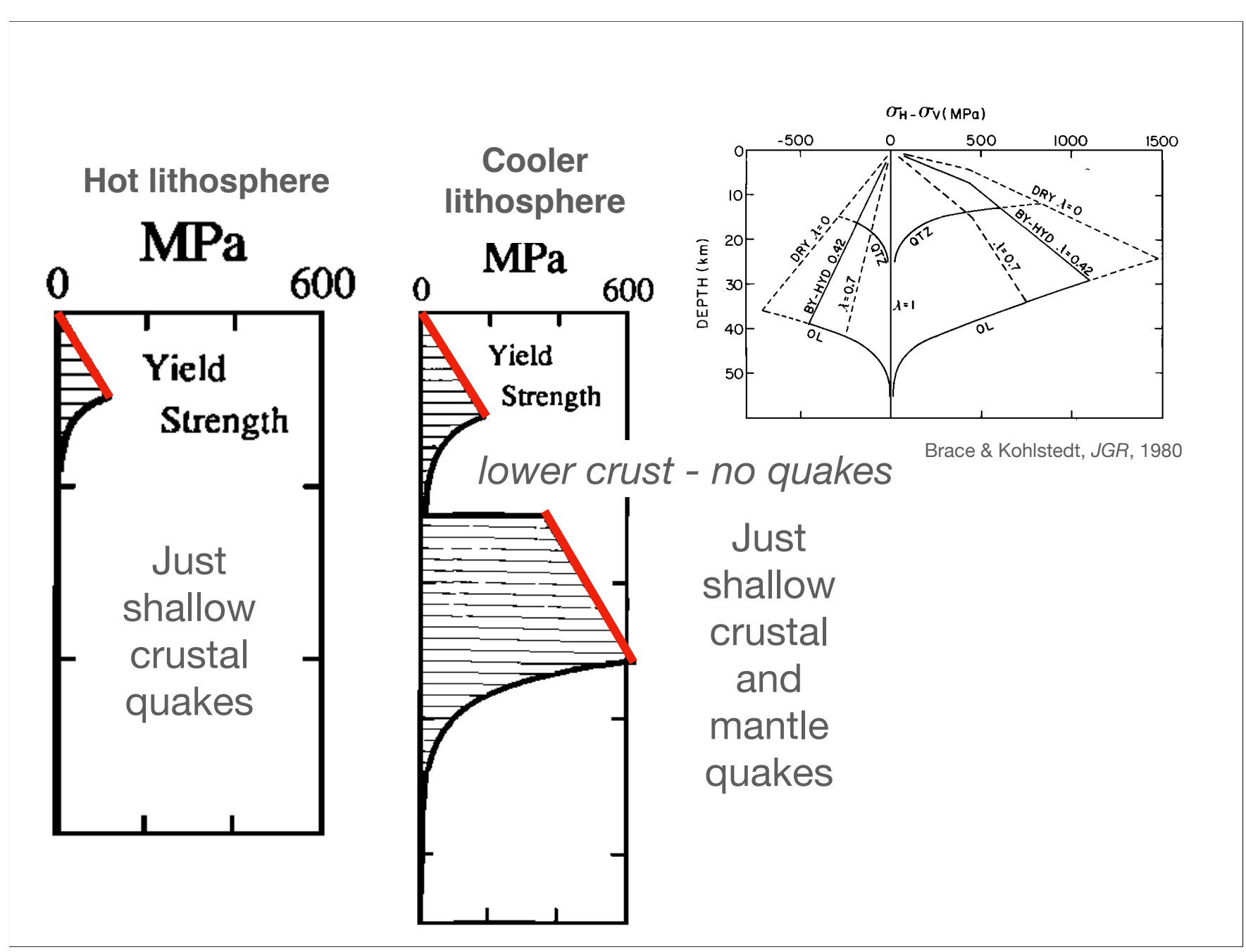

A lower geotherm might allow olivine based rheology in the mantle to fail with quakes, but the silica-rich lower crust should still fail ductilely. 


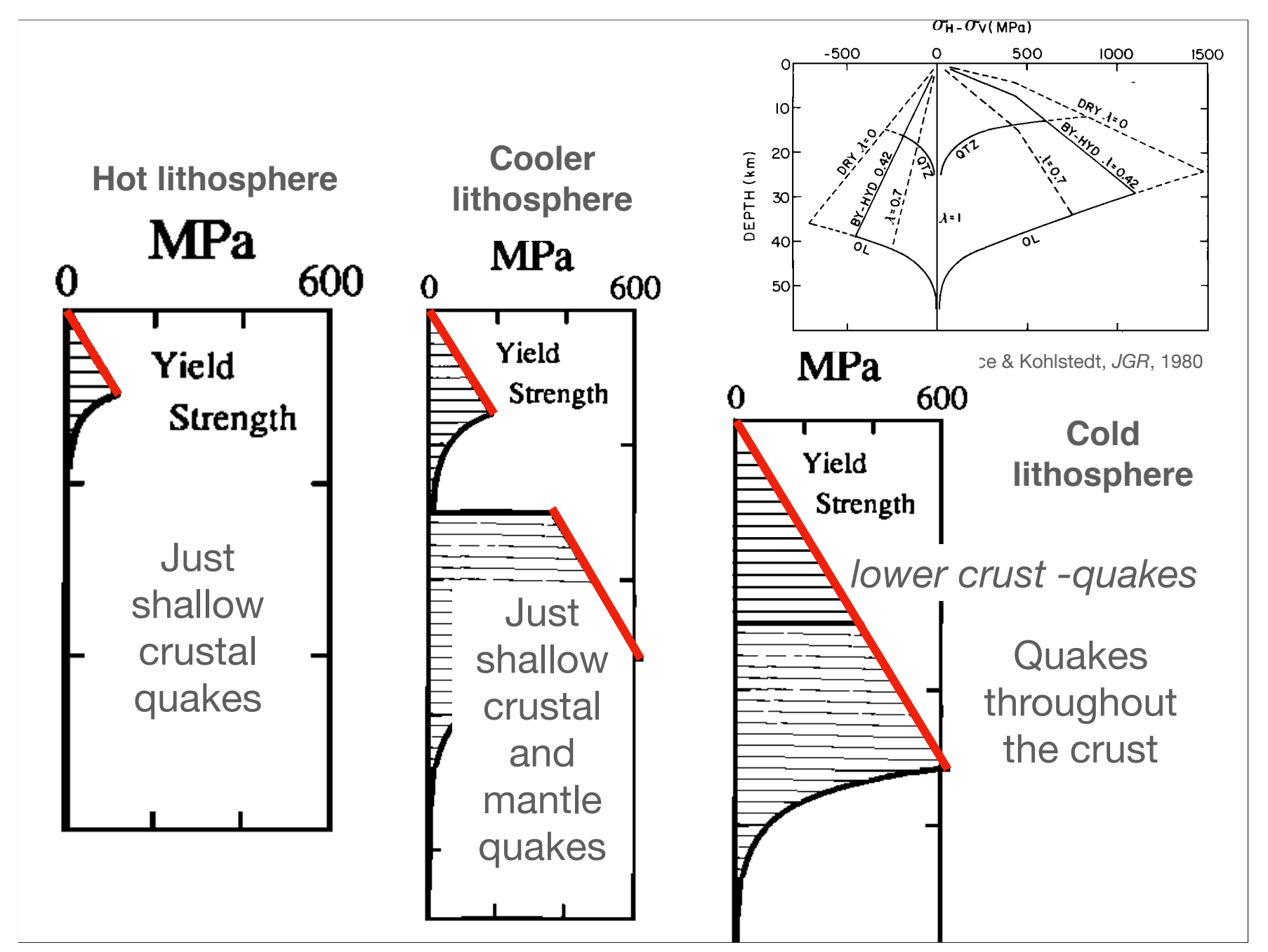

A really cold geotherm should result in seismicity throughout the crust-which would include the upper crust. 
Three Questions:

1. How special is this?-Seems pretty special

2. How might this work? - Not simple thermal effect

3. What might this mean for regional tectonics?

SNEP earthquake depths, Foothills cluster
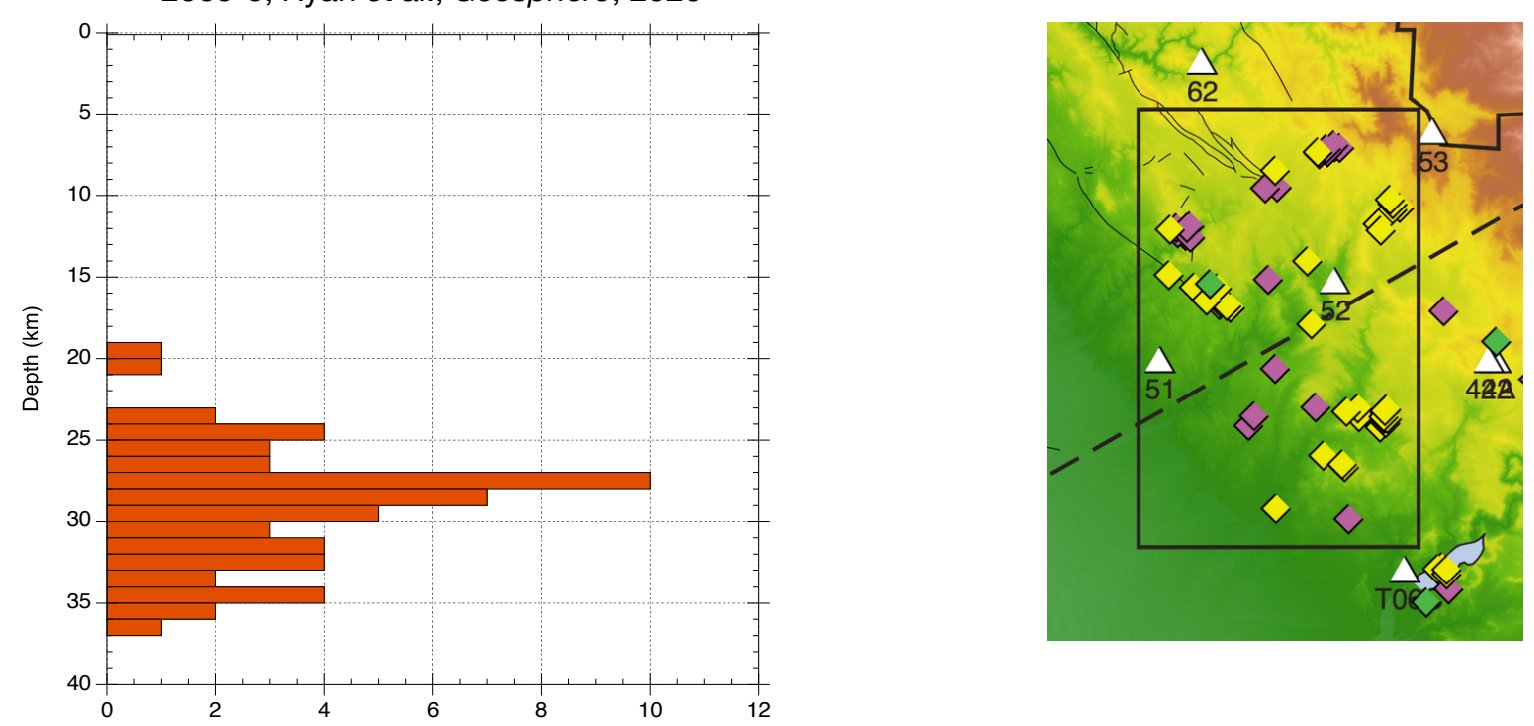

So this distribution of quakes is not easily reconciled with vertically uniform strain and a cold geotherm. What other possibilities are there? 


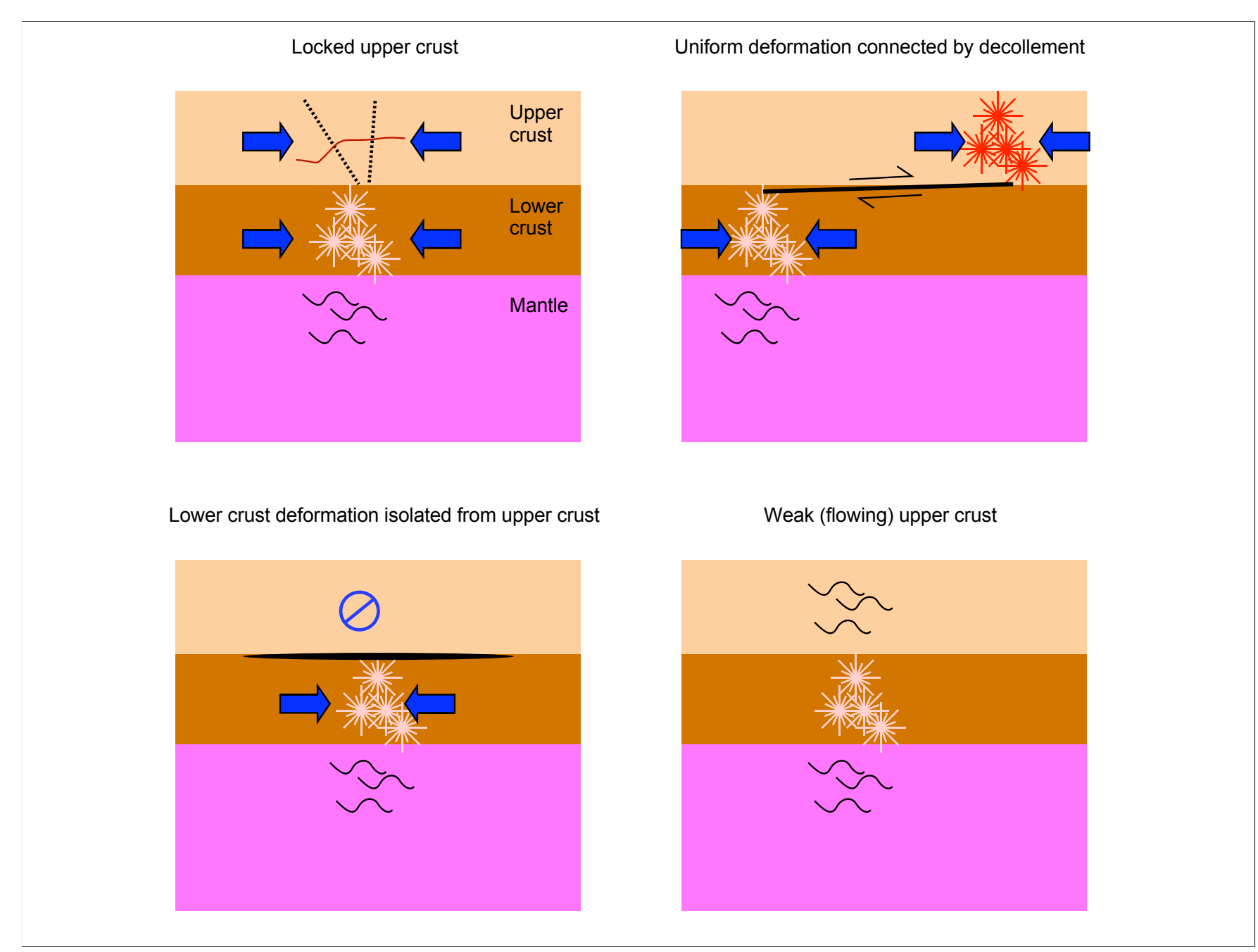

Some possibilities. Note the top two possibilities would suggest that the stress field orientation would be uniform and presumably similar to surroundings. 


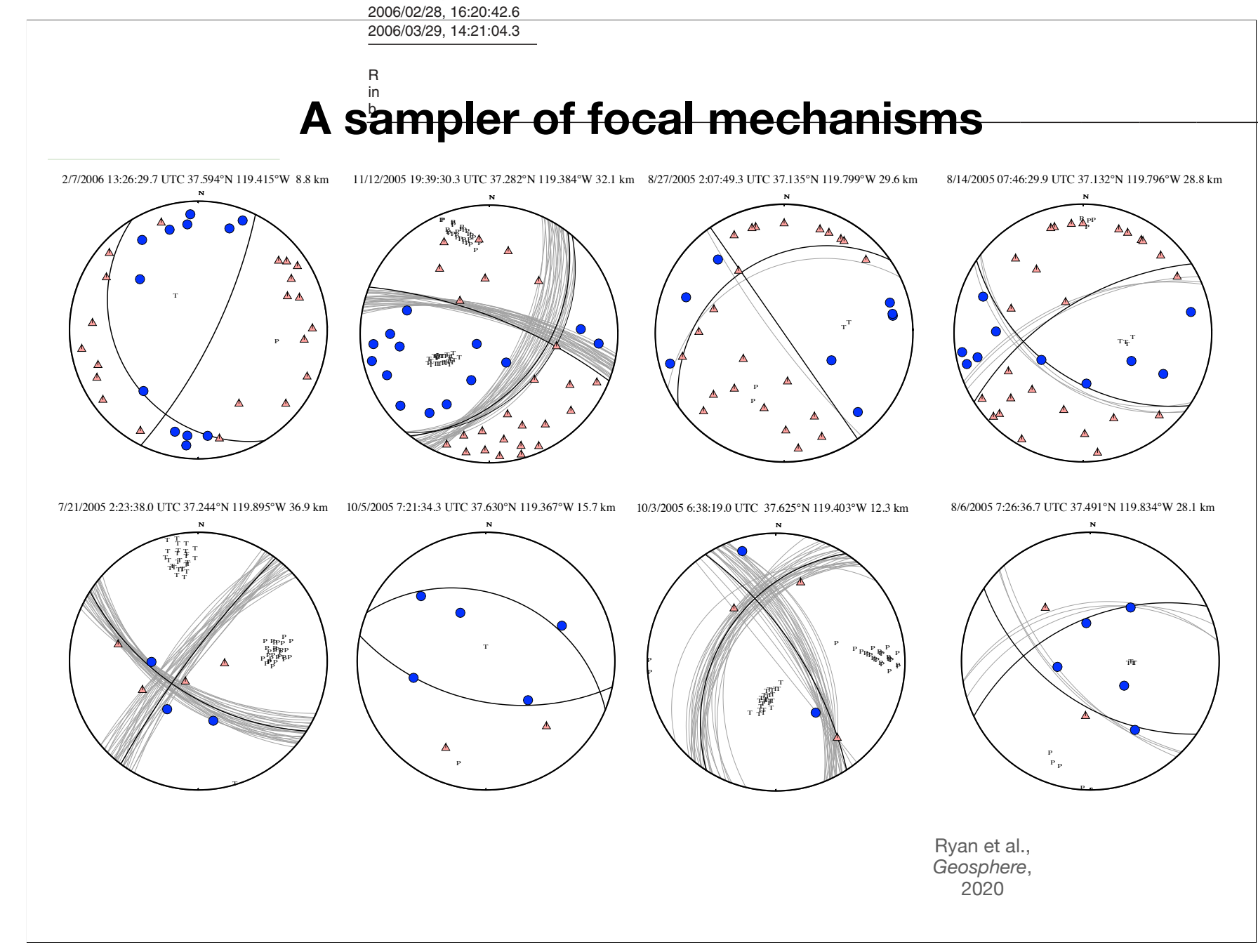

A sampler of focal mechanisms. Note tendency towards thrust/reverse solutions. 


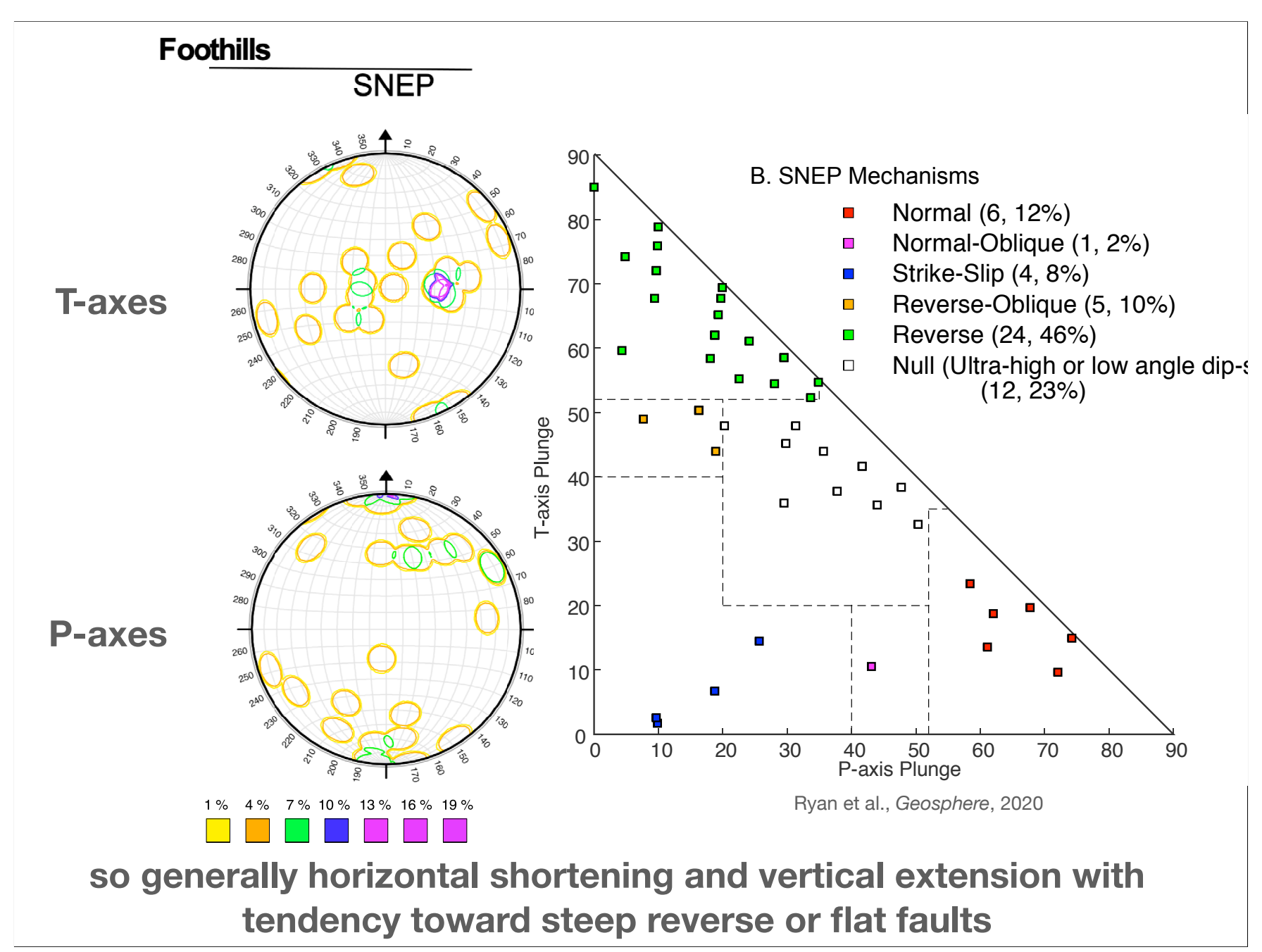

Also the mechanisms are not trending towards strike-slip. 


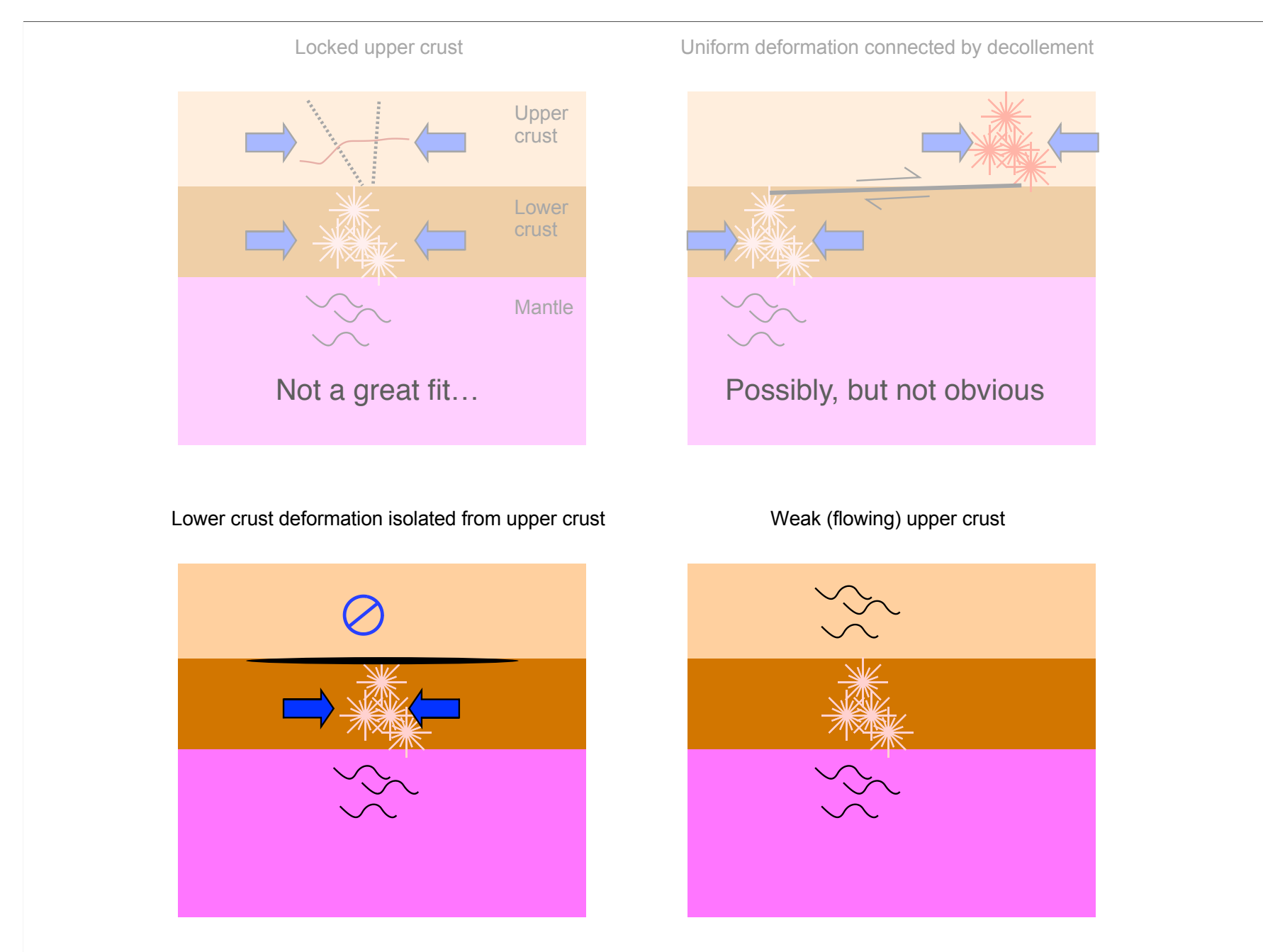

So top two not great. How about the bottom two? 


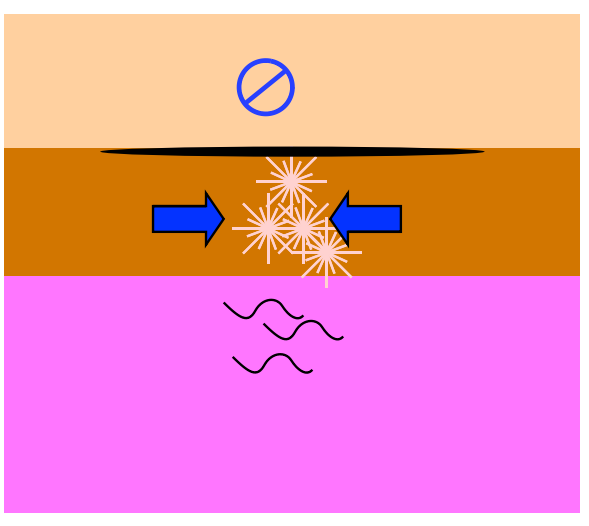

Plausible if driven from below

Consistent with focal mechanisms

What is top detachment?

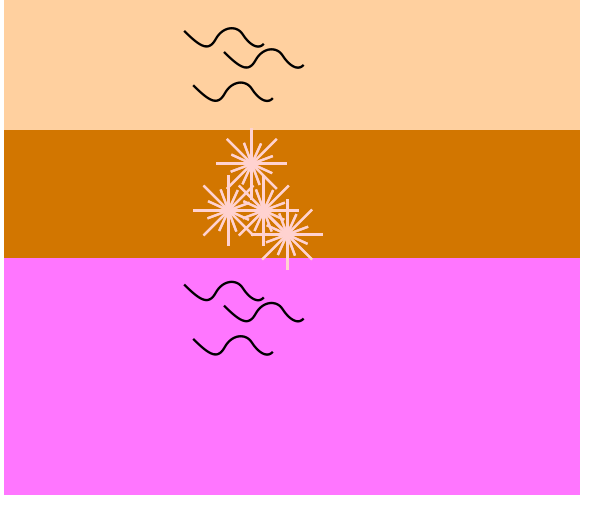

Physics of a "fluid" upper crust?

Would require reexamination of understanding of rheology in low-strain rate regions.

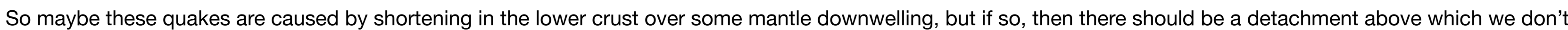
directly image. The alternative is that there is some unusual rheology in the upper crust that does not fail seismically. 
Three Questions:

1. How special is this?-Seems pretty special

2. How might this work? -Different rheology or above a drip?

3. What about regional tectonics?-possible foundering start?

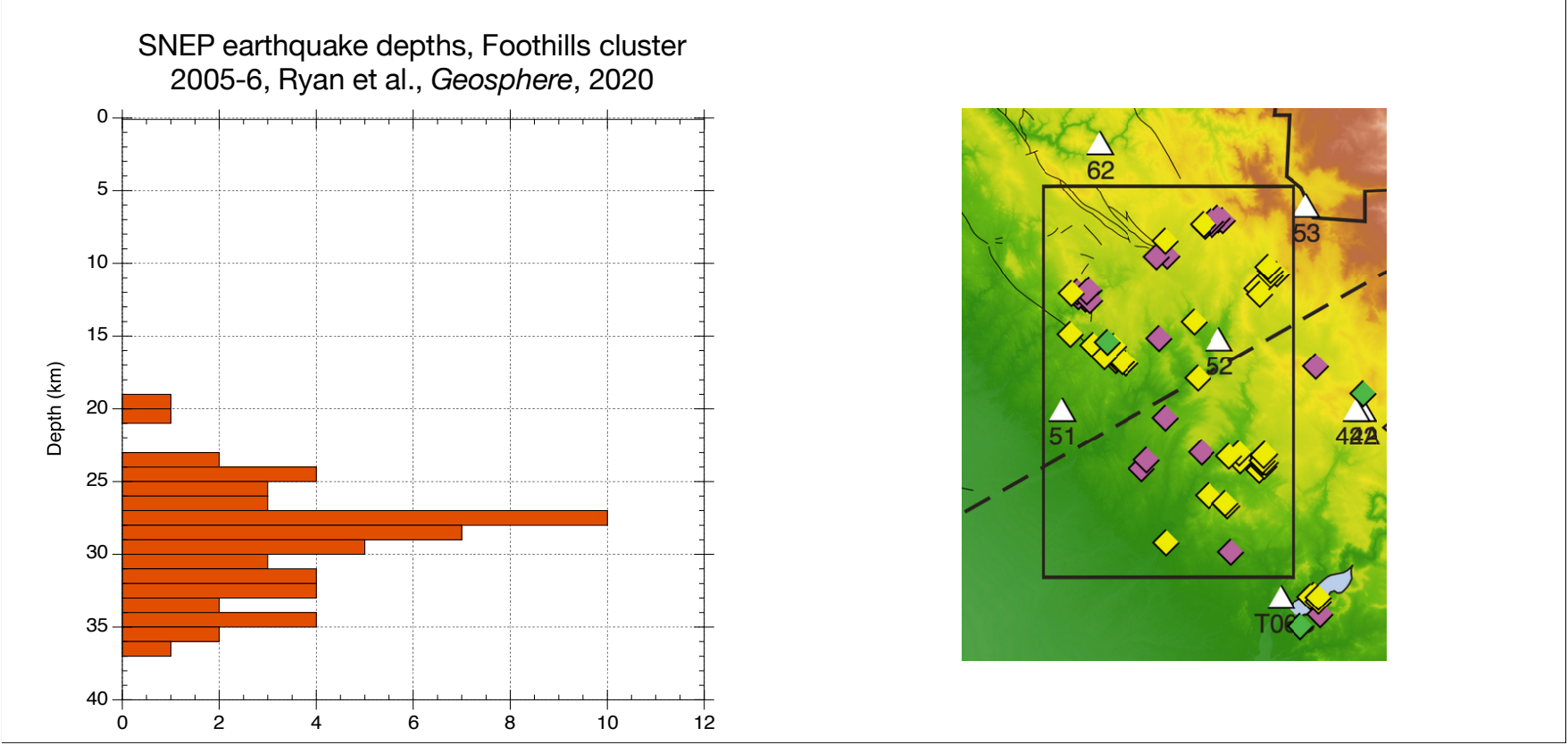

So this seems a worthy target of study. [Oral talk ended here] 


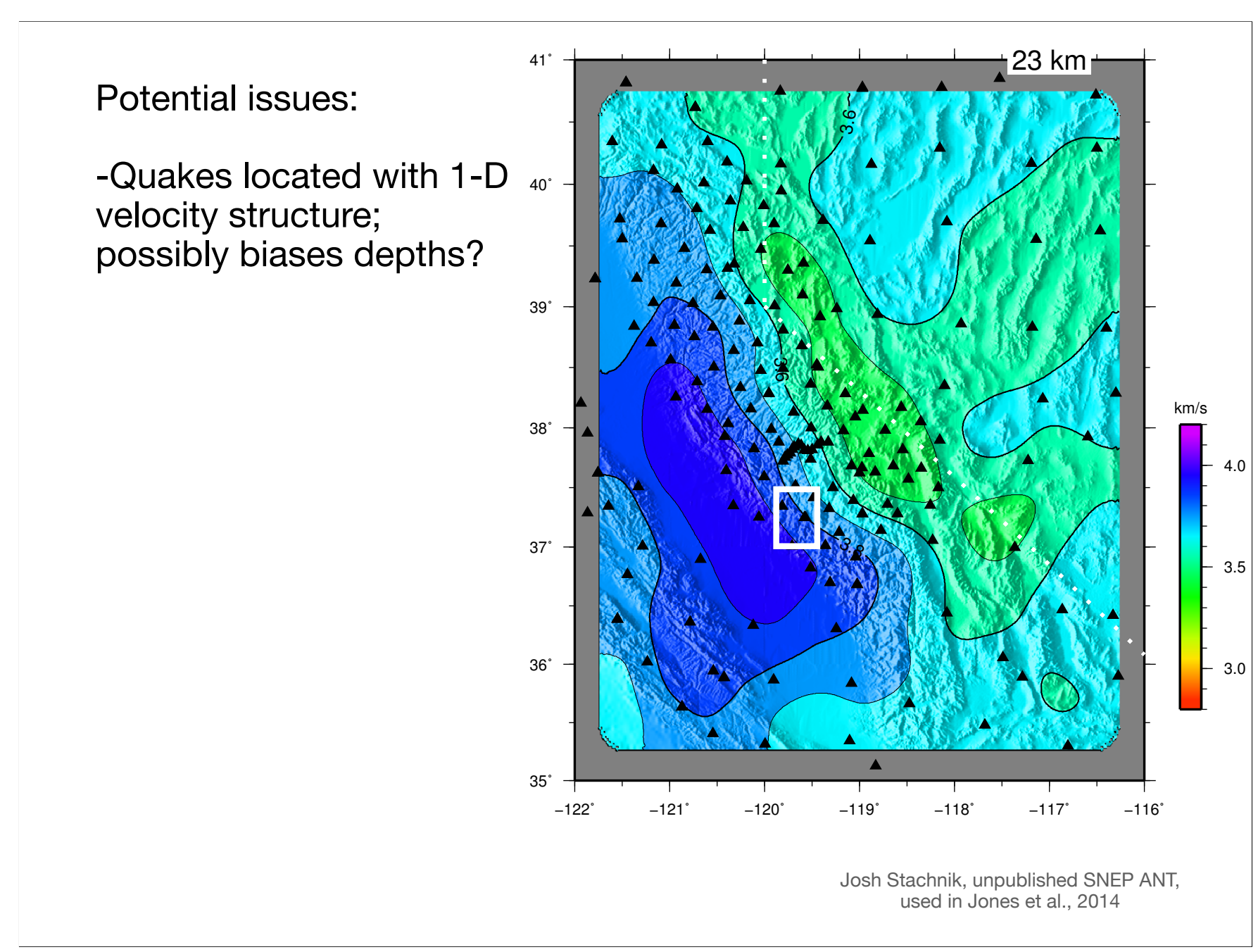

[Not shown in talk]. All the previous seismicity was located in a 1-d model, but there are pretty profound variations in crustal velocities; would be good to redo this in 3-D. 


\section{Conclusions}

Sierra foothills has a persistently strange cluster of earthquakes limited to the lower crust.

This might be globally unique: does it reveal hitherto unrecognized rheologies?

Focal mechanisms suggest a possible horizontal shortening in the lower crust.

Is this the start of delamination or foundering?

More work could examine the broader extent of these events suggested from ANSS catalog. 